\title{
Editorial
}

\section{The Canadian Incidence Study of Reported Child Abuse and Neglect: a partnership}

\author{
Lil Tonmyr, PhD, Guest Editor
}

Tweet this article

Child maltreatment is a public health issue of great importance. It is also a complex issue to define, identify and respond to. Views differ regarding families' rights to self-determination versus children's rights to protection from harm. Conflicting value systems and perceptions give rise to spirited public and legal debate. Child welfare agencies, mandated to protect children from harm, are criticized for inappropriately interfering in some situations and not intervening quickly enough in others.

Although child welfare agencies have the primary task of protecting children from harm in Canada, roles and responsibilities often involve social welfare, health, education, justice and law enforcement personnel. Child welfare legislation is a matter of provincial and territorial jurisdiction, and services are delivered through municipal and/or regional organizations. Child welfare services to First Nations children living on reserve are funded by Aboriginal Affairs and Northern Development Canada, either through First Nations child and family agencies or provincial and territorial governments' services where no First Nations agencies exist.

Although there have been advances in understanding child maltreatment, this field is relatively new: although the effects of physical abuse on children came to widespread attention in the 1960s, it was not until the next decade that their association with mental health problems was recognized. To date, little research has been conducted on possible long-term physical consequences of child maltreatment, such as chronic conditions and diseases. Studies based on Canadian data are particularly rare, especially in the area of intervention research.

A child maltreatment surveillance system provides a crucial tool to help address some of these complexities. It establishes consistent definitions of forms of child maltreatment (neglect, exposure to intimate partner violence, emotional maltreatment, physical and sexual abuse). It provides data for everyone involved in the response to understand the situation, and monitor and adapt programs and policies to better address the identified needs.

In the mid-1990s, Health Canada's Family Violence Prevention Unit commissioned a study to assess the possibility of collecting child maltreatment data from child welfare agencies across Canada. A Health Canada group responsible for maternal and child health surveillance built on the results of this study. This group consulted widely with provincial and territorial partners to build a surveillance system, resulting in a truly collaborative effort that led to the implementation of the Canadian Incidence Study of Reported Child Abuse and Neglect (CIS). ${ }^{1-2}$ This was a remarkable accomplishment considering the challenge of working with multiple partners, different legislative frameworks and the stigma that often accompanies the experience of child maltreatment.

The CIS captures data on child maltreatment investigations conducted by child welfare workers across Canada as well as the health and socioeconomic issues facing caregivers and children. In addition, it provides information about the systems' response to the child's plight.

Data collection for the CIS started in $1998^{3}$ and continued in $2003^{4}$ and 2008. ${ }^{5}$ Since 2004, the CIS continued as a surveillance system under the Public Health Agency of Canada. Preparation for CIS-2018 is ongoing.

CIS has always been dynamic and has constantly improved between cycles. Refining the measures of physical abuse and emotional maltreatment was one of the improvements introduced in 2003. Work spearheaded by Dr. B. Fallon, one of the key CIS researcher-collaborators of the CIS, led to the 2008 introduction of investigations of risk of future child maltreatment. ${ }^{6}$ Furthermore, numerous studies using CIS data have been used to inform policy and make decisions about best practices. ${ }^{7-9}$ CIS utility continues to be highly valued by policy makers and researchers.

It is with great pleasure that I introduce this section of the special issue of Health Promotion and Chronic Disease Prevention in Canada: Research, Policy and Practice, which is dedicated to the CIS, a key component of the Public Health Agency of Canada's surveillance programs. This is the first part of the special issue on child maltreatment; the second section highlights child maltreatment prevention with special attention to the Nurse-Family Partnership (NFP). The invited commentary of the second section describes Canada as testing the NFP's effectiveness outside of the United States. ${ }^{10}$

\section{Author reference:}

Surveillance and Epidemiology Division, Public Health Agency of Canada, Ottawa, Ontario, Canada

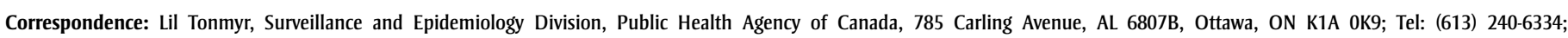
Email: Lil.Tonmyr@phac-aspc.gc.ca 
This section focusses on child maltreatment surveillance:

- The first article reviews recent findings stemming from peer-reviewed analysis of the CIS and provincial and territorial data. Potter et al. ${ }^{11}$ found that the quantity and quality of analysis continues to improve. They discovered that "newer" forms of child maltreatment such as neglect, exposure to intimate partner violence and emotional maltreatment have garnered more attention in recent years.

- The second article emphasizes that sexual abuse is an issue that requires multidisciplinary collaboration to resolve. For instance, joint investigations between child welfare and police are used as an upstream approach to enable better health outcomes for victims. Tonmyr and Gonzalez ${ }^{12}$ portray the characteristics of these investigations as captured in the CIS.

- The invited commentary, by Drs. Leeb (Centers for Disease Control and Prevention) and Fluke $^{13}$ (University of Colorado), provides international context to child maltreatment surveillance.

The CIS has proven to be an important surveillance and research tool. It provides important information about the children and families investigated by child protection services as well as a snapshot of the occurrence of child maltreatment in Canada at a specific time based on crosssectional data. To follow a sample of the children in the CIS over time would provide a better understanding of longterm outcomes of child maltreatment and the systems response. Maybe this can be a future improvement?

\section{References}

1. Phaneuf G, Tonmyr L. Status Report. New research initiatives from the Child Maltreatment Division. Chronic Dis Can.1998; 19(2):71-2.

2. Choi BC, Wigle DT, Johansen H, et al. Status Report Retracing the history of the early development of national chronic disease surveillance in Canada with a focus on the Laboratory Centre for Disease Control (LCDC) 1972-2000. Health Promot Chronic Dis Prev Can. 2015;35(2):35-44.
3. Trocmé N, MacLaurin B, Fallon B, et al. Canadian Incidence Study of Reported Child Abuse and Neglect: final report. Ottawa (ON): Minister of Public Works and Government Services Canada; 2001.

4. Trocmé N, Fallon B, MacLaurin B, et al. Canadian Incidence Study of Reported Child Abuse and Neglect - 2003: Major findings. Ottawa (ON): Minister of Public Works and Government Services Canada; 2005.

5. Public Health Agency of Canada. Canadian Incidence Study of Reported Child Abuse and Neglect 2008: Major findings. Ottawa (ON): Public Health Agency of Canada; 2010.

6. Fallon B, Trocmé N, MacLaurin B, Sinha V, Black T. Untangling risk of maltreatment from events of maltreatment: an analysis of the 2008 Canadian Incidence Study of Reported Child Abuse and Neglect (CIS-2008) Int J Ment Health Addiction. 2011;9:460-79.

7. Tonmyr L, Martin WK. How has child maltreatment surveillance data been used in Canada? Health Res Policy Syst. 2014;12 (1):65:1-9.

8. Tonmyr L, Jack SM, Brooks S, Williams G, Campeau A, Dudding P. Utilization of the Canadian Incidence Study of Reported Child Abuse and Neglect in child welfare agencies in Ontario. Chronic Dis Inj Can. 2012;33(1):29-37.

9. Tonmyr L, Ouimet C, Ugnat AM. A review of findings from the Canadian Incidence Study of Reported Child Abuse and Neglect (CIS). Can J Public Health. 2012;103(2):103-12.

10. Mikton C. Commentary. Adapting and retesting evidence-based child maltreatment prevention programs: a case study in Canada. Health Promot Chronic Dis Prev Can. 2015;35(8/9):168-70.

11. Potter D, Nasserie T, Tonmyr L. A review of recent analyses of the Canadian Incidence Study of Reported Child Abuse and Neglect (CIS). Health Promot Chronic Dis Prev Can. 2015;35(8/9):119-29.

12. Tonmyr L, Gonzalez A. Correlates of joint child protection and police child sexual abuse investigations: results from the Canadian Incidence Study of Reported Child Abuse and Neglect-2008. Health Promot Chronic Dis Prev Can. 2015;35(8/9):130-7.
13. Leeb R, Fluke J. Commentary. Child maltreatment surveillance: enumeration, monitoring, evaluation and insight. Health Promot Chronic Dis Prev Can. 2015;35(8/9):138-40. 